\title{
The Prevalence of Penile Abnormalities in Erzurum, Turkey O Akgun ${ }^{1 *}, \mathrm{H}^{\text {Acemoglu }}{ }^{2}, \mathrm{Z} \mathrm{Kosan}^{3}$, O Calıkoglu ${ }^{3}, \mathrm{HB}_{\text {Tanir }}^{4}$
}

\begin{abstract}
Epidemiologic studies have suggested that the incidence of congenital penile anomalies, particularly hypospadias, is increasing in the last three decades. In this study we aimed to assess the prevalence of congenital penile anomalies (CPA). Risk factors, which were thought to be related, were examined in male children attending school and nursery in the Northeast of Turkey. A total of 2040 male students from 14 nurseries and 18 primary schools in the Erzurum city urban Center/ Turkey participated in the study. All children were examined by one single expert doctor, a pediatric surgeon, in a room which was previously isolated by the school and at a suitable temperature. The total penile abnormalities, penile torsion and hypospadias prevalances were found to be $7.3 \%, 6.52 \%$ and $0.78 \% \ddot{\mathrm{u}}$, respectively. The frequency of genitoscrotum abnormalities in families (father and siblings) was found to be $4.3 \%$ for hypospadias. The degree of the penile torsion was at the most 45 with $32 \%$ and 90 with $25 \%$. The least was 70 and 120 degrees with $0.78 \%$. The effects of environmental agents on the development of congenital abnormalities have not been researched in our country. Publications, which indicate an increase in CPA incidences in various geographical regions over a short period of 30 years does not make it possible to render this situation by way of genetic transfer. On the other hand, contrary to some publications, our current study shows a high number of CPA in other family members form the same family, nevertheless, this situation cannot be explained with genetic transfer as it does not contain statistical meaning. However, an explanation with environmental contamination is possible.
\end{abstract}

For us to find CPA incidences in our study parallel to the highest value in the world in general puts forth that the use of environmental agents used in our country and region and its widespread should be put under control and that further studies should be carried out.

Keywords: Children, hypospadias, penile abnormalities

From: ${ }^{1}$ Department of Pediatric Surgery, ${ }^{2}$ Department of Medical Education, ${ }^{3}$ Department of Public Health, Ataturk University School of Medicine, Turkey, Erzurum and ${ }^{4}$ Konya Beyhekim State Hospital, Turkey, Selçuklu, Konya.

Correspondence: Dr O Akgun, Department of Pediatric Surgery, Ataturk University School of Medicine, Turkey, Erzurum. Tel: + 9044234474 00, Fax: + 904422361301

E-mail: ak_oral@hotmail.com 


\section{INTRODUCTION}

Common types of Congenital penile anomalies (CPA) in children are; Hypospadias, Penile chordee, Penile curvature, Penile torsion, Epispadias, Micropenis, Hidden penis, Ambigous genitalia, Apenia and Unspecified genital or penile anomalies.

In addition to the variation of frequency depending on the different race and geographical regions in the world in general, the incidence rate in 2005 in the United States of America (USA) weighted at 7.8/1000 newborns. The weighted incidence increased from 7.0/1000 newborns from $1988-1991$ to $8.3 / 1000$ from 1997-2000 (1). Although there are no conclusive data in Turkey regarding CPA incidences, there are publications indicating that hypospadias exists in $1.29-2.60 / 1000$ boys.

The penile urethra forms as a result of fusion of the medial edges of the endodermal urethral folds $(2,3)$. At this time of the external genitale development it is widely opened to affects of the maternal drug use and environmentally chemical disruptors. Epidemiologic studies have suggested that the incidence of CPA, particularly hypospadias, is increasing. There is a worldwide increase in incidences in the last three decades. The increasing incidence over the past 30 years of male reproductive tract abnormalities co-occurring with the increasing production and use of synthetic chemicals has raised concerns that environmental factors with antiandrogenic activity may play a role in the aetiology of these problems [hypospadias, undescended testes, decreasing sperm count] $(2,4,5)$. The only treatment of hypospadias and other CPA is surgical repair of the anatomical defect, there is no consensus on the surgical repair technique however. There are also too many surgical options described in publications due to the lack of knowledge about the aetiology.

In this study, we aimed to assess the prevalence of congenital penile anomalies. Risk factors, which were thought to be related, were examined in male children attending school and nursery in the Northeast of Turkey. 


\section{MATERIALS AND METHODS}

\section{Study site}

A cross-sectional epidemiological study was designed in central Erzurum Province, Eastern Turkey. According to the Regional Directorate of Education, the number of primary school students in the Erzurum urban city center was 30603.

\section{Sampling}

The total size of the sample was calculated by using the formula of Kish and Leslie $(\mathrm{s}=\mathrm{Z} * \mathrm{Z}(\mathrm{P}(1-\mathrm{P})) /(\mathrm{D} * \mathrm{D}))$ by using the software of Epi Info version 3.4.3 (Kish L Survey Sampling. New York. John Wiley and Sons Inc, 1965). The total number of subjects was determined as $2238(\mathrm{~d}=0.07, p=0.3, \alpha=0.05$, with $10 \%$ additional subjects $)$.

The distribution of the total sample size within the school was calculated according to the number of students in each school.

\section{Subjects and data collection}

Demographic information, simple medical data's, information towards the reasons of abnormalities in question and a questionnaire towards obtaining the parent's consent was given to the children to take to their parents.

All children participating in the study were examined by one single expert doctor, a pediatric surgeon, in a room which was previously isolated by the school and at a suitable temperature. Firstly, the lengths of the penis and testicular volumes were recorded. 
Following this, the groin and scrotum regions were examined in standing, lying and kneeling positions. The length of the penis was examined in an elongated position with the help of a ruler placed on the ramus pubise and in uncircumcised children, the length between the ramus pubis and glans penis was measured and recorded with the preputium pulled back. The testicular volume was however determined through using a Prader's Orchidometer made-up of plastic testicals of different dimensions.

Physical examinations in the standing and lying positions were carried out. Hypospadias was described as being more proximal than where the urethral mean should be and ventral opening. As for the penile torsion, those above $45^{\circ}$ were accepted as pathological.

\section{Ethical issues}

All of the subjects were informed about the nature and aim of the study. Subjects who accepted to participate provided written informed consents. An authorization was provided by the Regional Directorate of Education of Erzurum Province. The study was approved by the ethics committee of the university hospital. The school administration and teachers were informed about the study following the consent of the governorship and ethics committee. Information about the pathological cases was given to the school administration, teachers and families, thereafter, treatment for these children were provided.

\section{Statistical analysis}

Data was expressed in numbers, percentages, mean and standard deviation (SD). All questionnaires were checked and those incomplete were excluded. The data was entered to SPSS 18.0 (SPSS, Inc, Chicago, IL, USA). The penile abnormalities and age, the number of 
siblings, which child in line they were, birth term, birthweight, intake of breast milk, consanguineous marriage, mothers menstruation age, pregnancy age, mothers occupational status, mothers education, fathers education and the family's monthly income was analysed using the Chi-squared test and the penile torsion and the left and right testicular volume of elongated penis length with hypospadias in independent groups were analysed using the $t$-test, $p$-value under 0.05 was considered to be significant.

\section{RESULTS}

A total of 2040 male students from 14 nurseries and 18 primary schools in the Erzurum urban Center participated in the study. The rate of obtained sample volume was found to be $91.2 \%$ and the average age was $8.29 \pm 2.22(3-12)$. The category distribution of children is given in Table 1.

Table. 1: Grade distribution of study population.

\begin{tabular}{lcc}
\hline \multirow{2}{*}{ School grade } & \multicolumn{2}{c}{ Frequency } \\
& n & \% \\
\hline Pre-school & 384 & 18.82 \\
$1^{\text {st }}$ Grade & 379 & 18.58 \\
$2^{\text {nd }}$ Grade & 378 & 18.53 \\
$3^{\text {rd }}$ Grade & 338 & 16.57 \\
$4^{\text {th }}$ Grade & 295 & 14.46 \\
$5^{\text {th }}$ Grade & 266 & 13.04 \\
\hline TOTAL & & \\
\hline
\end{tabular}


The total penile abnormalities, penile torsion and hypospadias prevalence's were found to be $7.3 \%, 6.52 \%$ and $0.78 \% \ddot{u}$, respectively, given in (Table 2 and Fig. 1). When some of the risk factors, which are thought to be caused by penile abnormalities, were analysed, there was a difference in the borders, in terms of penile abnormality prevalence age groups $(p=0.05)$.

Table. 2: 2013 Annual prevalence of penile abnormalities in Erzurum (study population is 2040)

\begin{tabular}{lcc}
\hline Penile abnormalities & Number of cases $(\mathbf{n})$ & Percentile $(\mathbf{n} / \mathbf{2 0 4 0})$ \\
\hline Penile torsion & 133 & 6.5 \\
Hypospadias & 16 & 0.78 \\
\hline TOTAL & $\mathbf{1 4 9}$ & $\mathbf{7 . 3 0}$ \\
\hline
\end{tabular}

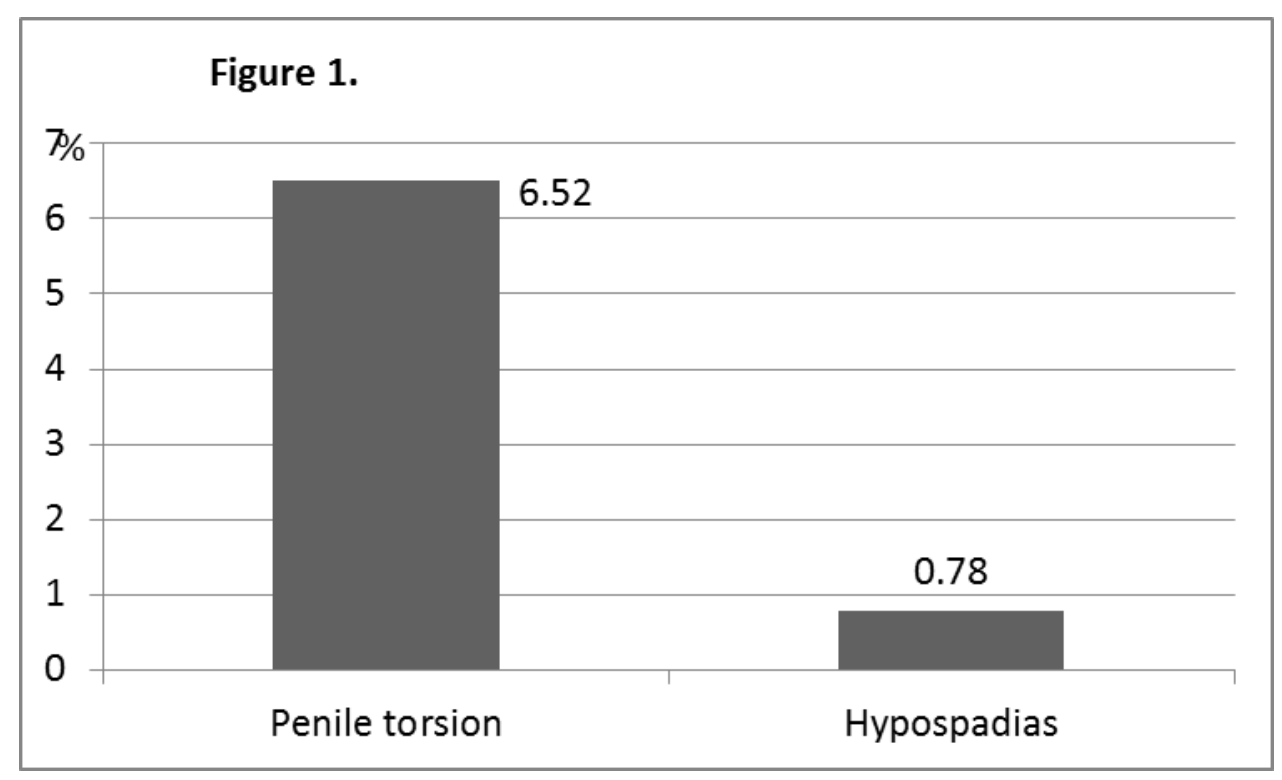

Fig: 1. The prevalence of penile abnormalities in Erzurum, 2013. 
This difference was found to originate from the 4-9 age group after further analysis that were carried out $(p=0.008)$. It was also found that there was no statistics with the number of siblings, which child in line they were, birth term, birthweight, intake of breast milk, consanguineous marriage, mothers menstruation age, pregnancy age, mothers occupational status, mothers education, fathers education and the family's monthly income $[p>0.05]$, (Table 3).

Table. 3: Assessment of risk factors with penile abnormalities

\begin{tabular}{|c|c|c|c|c|c|c|}
\hline & & \multicolumn{4}{|c|}{ Penile anomaly } & \multirow[b]{3}{*}{$p$} \\
\hline & & \multicolumn{2}{|c|}{ Negative } & \multicolumn{2}{|c|}{ Positive } & \\
\hline & & $\begin{array}{c}\text { Number of } \\
\text { cases }(\mathbf{n})\end{array}$ & $\begin{array}{l}\text { Percentile } \\
(\mathbf{n} / \mathbf{2 0 4 0})\end{array}$ & $\begin{array}{c}\text { Number of } \\
\text { cases }(\mathbf{n})\end{array}$ & $\begin{array}{l}\text { Percentile } \\
(\mathbf{n} / \mathbf{2 0 4 0})\end{array}$ & \\
\hline \multirow{10}{*}{ Age } & 3 & 81 & 97.59 & 2 & 2.41 & \multirow[t]{10}{*}{0.05} \\
\hline & 4 & 48 & 92.31 & 4 & 7.69 & \\
\hline & 5 & 85 & 90.43 & 9 & 9.57 & \\
\hline & 6 & 141 & 91.56 & 13 & 8.44 & \\
\hline & 7 & 262 & 89.12 & 32 & 10.88 & \\
\hline & 8 & 324 & 91.78 & 29 & 8.22 & \\
\hline & 9 & 357 & 92.49 & 29 & 7.51 & \\
\hline & 10 & 262 & 96.32 & 10 & 3.68 & \\
\hline & 11 & 234 & 94.74 & 13 & 5.26 & \\
\hline & 12 & 97 & 92.38 & 8 & 7.62 & \\
\hline \multirow{4}{*}{$\begin{array}{l}\text { Number of } \\
\text { Siblings }\end{array}$} & $0-1$ & 176 & 93.62 & 12 & 6.38 & \multirow[t]{4}{*}{ n.s } \\
\hline & 2 & 627 & 92.89 & 48 & 7.11 & \\
\hline & 3 & 541 & 93.76 & 36 & 6.24 & \\
\hline & 4 & 272 & 91.89 & 24 & 8.11 & \\
\hline \multirow{6}{*}{$\begin{array}{l}\text { Birth order rank } \\
\text { of the children }\end{array}$} & 1 & 646 & 91.5 & 60 & 8.5 & \multirow[t]{6}{*}{ n.s } \\
\hline & 2 & 589 & 94.24 & 36 & 5.76 & \\
\hline & 3 & 323 & 92.82 & 25 & 7.18 & \\
\hline & 4 & 162 & 91.01 & 16 & 8.99 & \\
\hline & 5 & 57 & 90.48 & 6 & 9.52 & \\
\hline & $6 \leq$ & 81 & 94.19 & 5 & 5.81 & \\
\hline \multirow{2}{*}{ Gestational Age } & Term (40 weeks) & 1595 & 92.2 & 135 & 7.8 & \multirow[t]{2}{*}{ n.s } \\
\hline & Post-term & 115 & 95.83 & 5 & 4.17 & \\
\hline
\end{tabular}




\begin{tabular}{|c|c|c|c|c|c|c|}
\hline & term (36-40 weeks) & 97 & 95.1 & 5 & 4.9 & \\
\hline Pre & erm (Before36 weeks) & 32 & 91.43 & 3 & 8.57 & \\
\hline \multirow{3}{*}{ Birthweight } & $<2500 \mathrm{gr}$ & 323 & 91.24 & 31 & 8.76 & n.s \\
\hline & $2500-4500 \mathrm{gr}$ & 1371 & 92.57 & 110 & 7.43 & \\
\hline & $>4500 \mathrm{gr}$ & 153 & 95.03 & 8 & 4.97 & \\
\hline \multirow{3}{*}{ Breast feeding } & No & 98 & 93.33 & 7 & 6.67 & n.s \\
\hline & $<4$ months & 372 & 91.4 & 35 & 8.6 & \\
\hline & $>4$ months & 1392 & 92.86 & 107 & 7.14 & \\
\hline \multirow{3}{*}{$\begin{array}{l}\text { First menstrual } \\
\text { age of mother }\end{array}$} & $<9$ year & 30 & 96.77 & 1 & 3.23 & n.s \\
\hline & $9-15$ year & 1242 & 92.62 & 99 & 7.38 & \\
\hline & $>15$ year & 297 & 93.4 & 21 & 6.6 & \\
\hline \multirow{2}{*}{$\begin{array}{l}\text { Consanguineous } \\
\text { marriage }\end{array}$} & Yes & 286 & 91.67 & 26 & 8.33 & n.s \\
\hline & No & 1586 & 92.86 & 122 & 7.14 & \\
\hline \multirow{6}{*}{$\begin{array}{l}\text { Pregnancy age of } \\
\text { mother }\end{array}$} & $15-19$ & 136 & 91.89 & 12 & 8.11 & n.s \\
\hline & $20-24$ & 580 & 92.21 & 49 & 7.79 & \\
\hline & $25-29$ & 562 & 94.14 & 35 & 5.86 & \\
\hline & $30-34$ & 325 & 93.66 & 22 & 6.34 & \\
\hline & $35-39$ & 152 & 91.02 & 15 & 8.98 & \\
\hline & $>40$ & 34 & 91.89 & 3 & 8.11 & \\
\hline \multirow[t]{2}{*}{ Mother's work status } & Yes & 233 & 93.20 & 17 & 6.8 & n.s \\
\hline & No & 1653 & 92.61 & 132 & 7.39 & \\
\hline \multirow[t]{2}{*}{ Mother's work status } & Yes & 233 & 93.20 & 17 & 6.8 & n.s \\
\hline & No & 1653 & 92.61 & 132 & 7.39 & \\
\hline \multirow{5}{*}{ Mother's education } & Illiterate & 202 & 91.40 & 19 & 8.6 & n.s \\
\hline & Primary School & 1022 & 92.66 & 81 & 7.34 & \\
\hline & Secondary School & 169 & 92.35 & 14 & 7.65 & \\
\hline & High School & 254 & 93.38 & 18 & 6.62 & \\
\hline & Graduate & 232 & 93.93 & 15 & 6.07 & \\
\hline \multirow{5}{*}{ Father's education } & Illiterate & 28 & 93.33 & 2 & 6.67 & n.s \\
\hline & Primary School & 458 & 91.42 & 43 & 8.58 & \\
\hline & Secondary School & 350 & 93.33 & 25 & 6.67 & \\
\hline & High School & 561 & 92.73 & 44 & 7.27 & \\
\hline & Graduate & 483 & 93.79 & 32 & 6.21 & \\
\hline \multirow{3}{*}{$\begin{array}{l}\text { Monthly family } \\
\text { income }\end{array}$} & $<527 \mathrm{TL}$ & 450 & 91.65 & 41 & 8.35 & \multirow{3}{*}{ n.s } \\
\hline & $527-1054 \mathrm{TL}$ & 695 & 92.05 & 60 & 7.95 & \\
\hline & $>1054 \mathrm{TL}$ & 720 & 94.24 & 44 & 5.76 & \\
\hline
\end{tabular}


The frequency of genitoscrotum abnormalities in families (father and siblings) was found to be $4.3 \%$ for hypospadias. Penile torsion was not found. The $50 \%$ of the Hypospadias mealar's was granüler and $41.7 \%$ was coronal located. The $56 \%$ of the penile torsion was on the left side. The degree of the penile torsion was at the most 45 with $32 \%$ and 90 with $25 \%$. The least was 70 and 120 degrees with $0.78 \%$ (Table 4).

Table 4. Penile abnormality properties

\begin{tabular}{|c|c|c|c|}
\hline & & $\begin{array}{l}\text { Number of } \\
\text { cases (n) }\end{array}$ & $\begin{array}{c}\text { Percentile } \\
\text { (n/total) }\end{array}$ \\
\hline \multirow{3}{*}{$\begin{array}{l}\text { Localization of the urethral } \\
\text { meatus }\end{array}$} & Glanuler & 6 & 50.00 \\
\hline & Coronal & 5 & 41.67 \\
\hline & Subcoronal & 1 & 8.33 \\
\hline \multirow{4}{*}{ Direction of penile torsion } & TOTAL & 12 & 100 \\
\hline & Counter clockwise & 58 & 43.94 \\
\hline & Clockwise & 74 & 56.06 \\
\hline & TOTAL & 132 & 100 \\
\hline \multirow{9}{*}{ Rotation degree } & $45^{0}$ & 41 & 32.03 \\
\hline & $60^{0}$ & 25 & 19.53 \\
\hline & $70^{0}$ & 1 & 0.78 \\
\hline & $75^{0}$ & 21 & 16.41 \\
\hline & $80^{0}$ & 5 & 3.91 \\
\hline & $90^{0}$ & 32 & 25.00 \\
\hline & $110^{0}$ & 2 & 1.56 \\
\hline & $120^{0}$ & 1 & 0.78 \\
\hline & TOTAL & 128 & 100 \\
\hline
\end{tabular}

The left and right testicular average volume was found to be less than those without penile torsion. For right testical $2.5 \pm 0.8 \mathrm{~mL}^{3}$ and $2.8 \pm 1.2 \mathrm{~mL}^{3}(p=0.02) ; 2.5 \pm 0.8 \mathrm{~mL}^{3}$ and $2.8 \pm 1.3 \mathrm{~mL}^{3}(p=0.01)$ can be given for the left testical, respectively. Statistically, no difference was found between both sides in terms of average testicular volumes in those with or without hypospadias $(p>0.05)$. The average elongated penis length for those with and without penile torsion and hypospadias were found to be statically familiar $(p>0.05$, Table $5)$. 
Table. 5: Penile length and testicular volume statistics comparison table

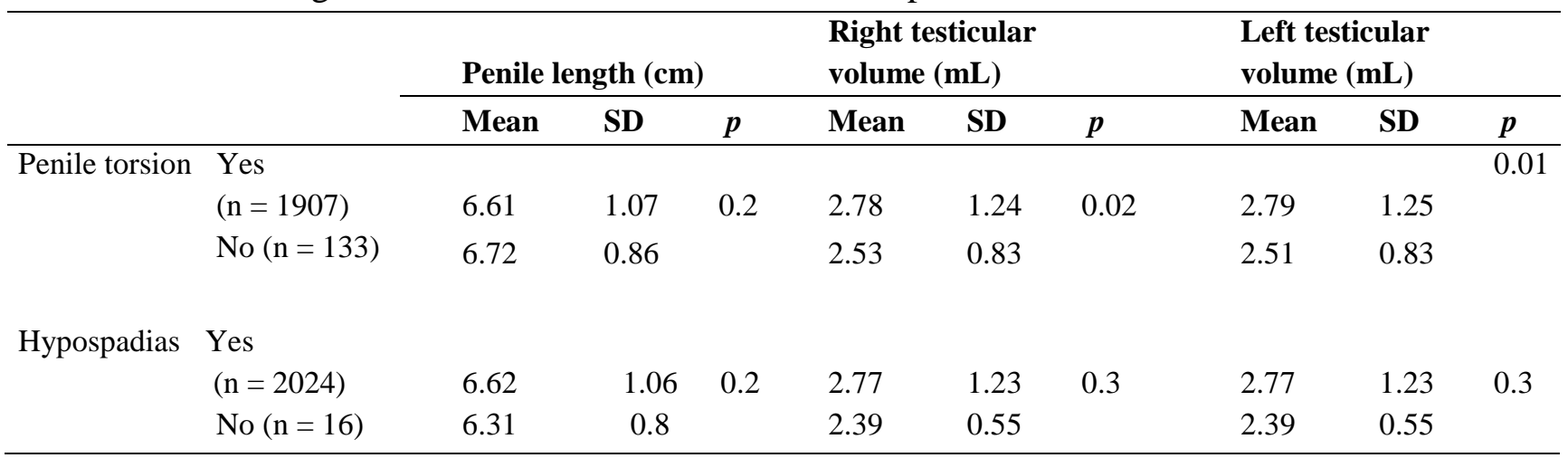

The six samples with penile torsion kept their problems even if they were circumcised. The 50\% (8/16) of families noticed the hypospadias abnormalities. It was determined that five of these were noticed at the age of under one year, one at the age of two and two at the age of four.

\section{DISCUSSION}

Congenital penile anomalies is known to be seen throughout the world at various frequencies at different geographical regions and races. There is no comprehensive study in Turkey, which puts forward the true prevalence of CPA. Our study is the first wide scope epidemiologic field study to be carried out in this area. The most wide scope study in the past was by Yücesan et al in 1993, which was a congenital abnormality combing of school children. However, the results of this study did not include our region.

Until 1970's the postulated reported prevalence of hypospadias was $0.3-0.8 \%$ of male births (6). Since the 1970's, multiple reports from several countries have shown an increase in the prevalence of hypospadias $(4,6,7)$. Lund et al in Denmark from 1977 to 2005, identified the prevalence of hypospadias increased from $0.24 \%$ in 1977 to $0.52 \%$ in 
2005, corresponding with an annual increase in prevalence of $2.40 \%$ (7). Nelson et al reported the weighted incidence increased from 7.0/1000 newborns in 1988 to 1991 to 8.3/1000 in 1997 in the USA (1). On the contrary to all publications regarding the general increase of hypospadias and CPA in the world, Fisch et al reported that retrospectively the total prevalence of hypospadias in New York State from 1992 to 2005, found no change (8). Prevalence percentage of hypospadias in prospective population-based studies or systematic surveys of hospital records shows geographic differences (9). A review of the literature revealed the incidence of hypospadias has ranged from 0.8 to 8.2 per 1000 live male births (10). Yucesan et al reported the prevalence of congenital abnormalities in 19750 Turkish school children and they found hypospadias was present in $0.66 / 1000$ school-aged children (11). In another study, Yesilipek et al (12) from Turkey have reported prevalence's of this abnormality to be $2.06 / 1000-2.60 / 1000$ neonates in Turkey. In the present study, the prevalence of hypospadias was found in about 7.8 per 1000 students. If we compare our results with Yucesan et al and Yesilipek et al reports, there is an increase in the last three decades in Turkey. If we compare our results with those from all over the world, our results are one of the highest reported to date. This variation may represents geographic and racial differences (13).

In our study, patients diagnosed with CPA were especially from the 4-9 age groups and this was found to be statistically significant. The reoccurrence of decline of CPA prevalence in children under the age of four leaves it impossible to explain this with genetic transmission. On the other hand, it gives rise to thought from a study carried out 4-9 years ago throughout the Erzurum urban city on children in groups found with high prevalence, to be effective in children of mothers who fell pregnant only at that period with the effect of a contaminating agent, which was temporarily effective. 
It is indicated that first degree relatives of individuals with Hypospadias are $10 \%$ likely to also be born with hypospadias (14-16). While in a study that Manson et al carried out could not find a significance difference between single and multiple births, they found that the frequency of a CPA risk in the first child was significantly higher in comparison to the families other children (14). Bauer et al indicated that in at least one person from the family of $4.2 \%$ of hypospadias patients have been stricken by the same illness (17). Our findings have put forward that only first degree relatives of $4.3 \%$ patients have CPA, which is a form of result that is supportive of those of Bauer et al (17). However, it has been determined that none of the first degree relatives of those with penile torsion had penile torsion and were not treated for this purpose. Moreover, the number of siblings in the household and in which line these children were among the siblings was queried.

A correlation could not be found between the presence of CPA and statistical number of siblings and in which line the children were to there siblings.

\section{Consanguineous marriage}

The rate of consanguineous marriages seen amongst the parents of children with congenital abnormalities was $8.9 \%$ while this figure was $8.2 \%$ amongst the parents of the rest of the children (18).

In consanguineous families and small case series have identified allelic variants in genes controlling androgen action and metabolism that cause hypospadias, but the relevance of these findings to the general population is unknown. Concern has also focussed on whether exposure to endocrine disrupting chemicals (EDC) with antiandrogenic activity is the cause of this increase (14).

Aschim et al found a borderline significant (48\%) increased risk of hypospadias when the parents were second cousins or closer, and declared that hypospadias was not uncommon 
in children of consanguineous parents (19). Aschim et al determined that there was a high hypospadias risk found which was at the border of a significant $48 \%$ probability in the parents, second degree cousins and much closer relative of hypospadias patients (19).

Friedman et al reported that, in instances where they found multiple cases of hypospadias in close relatives or in the family, they usually found parent consanguinity (20).

As for us, we determined in our study that there was a consanguineous marriage in 8.3\% of CPA patients. Consanguineous marriage is widespread in Erzurum urban city (18), where the study was carried out. Nevertheless, the low existence of CPA puts forth environmental pollution/contamination agents of the hypospadias aethiology to be more effective than genetic transfer.

\section{Term of birth and birthweight}

Carmichael et al stated that there was a serious increase in the risk of hypospadias in births before the gestational week (21). In the study of Gatti JM el al it was reported that the cause of SGA and patients accepted as neonatal Intensive Care unit (NICU) was seen to have hypospadias 10 times more than the general population. However, we did not find any statistical relevance between CPA gestational week and weight birth as Neto et al (22) and Czeizel et al (23) had stated. This case presumably could be due to $92 \%$ of the participants of our study being mature and born after the $36^{\text {th }}$ gestation week and $83 \%$ being born over 2500 gr.

\section{Breast milk intake}

It was determined that $68 \%$ of those in our study with CPA had taken at least four months of breast milk. However, a significant association between breast milk, nutrition and CPA was not found. 


\section{Mothers first menstrual age}

In our current study a research towards the mothers first menstrual age and the presence of CPA was carried out. There appeared no significance.

\section{Pregnancy age}

Some publications stress the existing relation between advanced mothers age and advancing prevalence of CPA (24) Pierik FH et al. A $50 \%$ increase in severe cases has been demonstrated in children of mothers $>35$ years old compared to mothers $<20$ years old $(14,24)$. Mean hypospadias rates in children of mothers 35 years old or older were significantly greater than those in children of mothers younger than 35 years (8). Even though there are many publications relating to the a significance between pregnancy age and hypospadias, it was determined that $84 \%$ of the mothers in our study fell pregnant in the 20-29 age group, however, no significant relevance could be found between CPA and a mothers pregnancy age.

\section{Mother's occupational status}

There are publications stating relevance between a mothers vocation and their child's CPA (25). The mothers occupational status was questioned during a survey conducted in our current study and as a result the mothers of $6.86 \%$ of children with CPA were working, however, we found this result to be not significant. On the other hand, the job type was not asked in the survey, which can be considered as a limitation of our study. A question whether the mothers field of work involved exposure to chemical pollution should have also been asked. 


\section{Educational status}

Parental educational status was questioned as a CPA risk factor in our survey. A previous study (Vrijheid et al 2003) reported that the mother's educational status was not a risk for CPA (26). A supporting this publication was not found in our study and the result was not found significant.

\section{Family's state of income}

When the families state of income was researched some publications found that the socio economic level had a significant relevance to CPA $(4,27)$. Pierik et al also stated that low socio-economic conditions were a risk for hypospadias (28). However, we determined in our current study that children with CPA were distributed homogenously into all income groups and on the contrary to current publications, no significant relevance between income level and CPA were found.

\section{Method of family planning}

Henderson et al reported that the high estrogen level in women exposed to diethylstilbestrole during the fertilizing stage negatively affects the development of genital organs (29). Damber et al reported that the continuing use of oral contraceptives after fertilization increases the estrogen level in the fetus (30). In contradiction to these publications, Noorgan et al reported that in the study they carried out found no relevance between the use of oral contraceptive by mothers and the increase of risk of hypospadias (9). In parallel to Norgaard et al (9) we could not find relevance between the development of CPA and the use of oral contraception in our study. 


\section{Implementation of vitro fertilization}

Women undergoing in vitro fertilization (IVF) procedures typically receive treatment with progesterone in the first trimester to support the pregnancy after embryo transfer (14). It was postulated that this treatment is the cause of increased risk for hypospadias following IVF procedures (16). Experimental studies have shown that progestin's administered to laboratory animals during pregnancy can cause hypospadias $(14,31)$.

A meta-analysis of human studies also did not find an association between progestin exposures and external genital anomalies in male infants (32). In addition, Ericson et al found that an increased risk for hypospadias was specific for intra-cytoplasmic sperm injection (ICSI), and not for all the other IVF procedures in which progestin support was administered (33). We could not find a relevance between IVF and the development of CPA, too.

\section{Use of drugs during pregnancy}

It has also been suggested that maternal exposure to progestin (ie, natural progesterone and synthetic progesterone and testosterone derivatives that produce biologic effects similar to those of progesterone) during early pregnancy may increase hypospadias risk by interfering with the production or action of fetal androgens, which are critical to normal closure of the urethra $(4,34)$.

This study observed an increased risk of second and third degree hypospadias among infants delivered to women who took progestin during early pregnancy to help them become pregnant or to prevent pregnancy complications or loss (34). 
In our study, another frequent reason of CPA was found to be penile torsion. Campbell suggested identifying the presence of penile torsion by referring to the position of the median raphe (35). In our experience, penile torsion can be easily identified from the orientation of the urethral meatus of an erect penis. The urethral meatus rotates accordingly in penile torsion, but it remains vertically oriented in pure ventral or lateral penile curvature (36).

In our study, the mean penile length was measured to be $6.61 \pm 1.07$. It is known that penile length has geographic differentiates in the world. Cheng et al reported that the mean penile length and diameter are slightly but significantly smaller in newborns of Chinese origin compared to newborns of Caucasian and East-Indian origins (37). Cinaz et al reported mean penile length $6.63 \pm 0.68$ for $7.1-8$ years old boys in Turkey (38). If we compare our results with Cinaz et al report, there is no difference between two studies.

In 2001, Skakkebæk et al put forth the hypothesis that some male reproductive disorders were interlinked and originated from a disturbed testicular development in utero (39). This hypothesis was called testicular dysgenesis syndrome (TDS). The TDS hypothesis was based on clinical, epidemiological and basic scientific evidence for a fetal origin of testis cancer, the well-established link between genital malformations in newborn boys and adult reproductive disorders, and on observations from experimental animal studies and wildlife such as urogenital abnormalities associated with exposure to environmental EDC such as phthalates, specifically decreased semen quality, and increased rates of testis cancer and hypospadias (8). Together with this existing evidence suggested that the prenatal period may be the most vulnerable phase in which impairment of testis differentiation may result in permanent adverse effects. There is a worldwide increase in incidence of CPA and hypospadias. Endocrine disrupting chemicals with antiandrogenic activity may be the cause of this increase. 
Effectively, in November, 2000, the US Food and Drug Administration no longer required that progestational drugs (which include natural progesterone and all synthetic progestin, other than progestin-containing products for contraception) carry a warning regarding genital defects (40).

The effects of environmental agents on the development of congenital abnormalities have not been researched in our country. Publications, which indicate an increase in CPA incidences in various geographical regions over a short period of 30 years does not make it possible to render this situation by way of genetic transfer. On the other hand, contrary to some publications, our current study shows a high number of CPA in other family members form the same family, nevertheless, this situation cannot be explained with genetic transfer as it does not contain statistical meaning. However, an explanation with environmental contamination is possible. For us to find CPA incidences in our study parallel to the highest value in the world in general puts forth that the use of environmental agents used in our country and region and its widespread should be put under control and that further studies should be carried out. 


\section{REFERENCES}

1. Nelson CP, Park JM, Wan J, Bloom DA, Dunn RL, Wei JT. The increasing incidence of congenital penile anomalies in the United States. J Urol 2005; 174 (4 Pt 2):1573-6.

2. Baskin LS, Ebbers MB. Hypospadias: anatomy, etiology, and technique. J Pediatr Surg 2006; 41: 463-72.

3. Wang MH, Baskin LS. Endocrine disruptors, genital development, and hypospadias. J Androl 2008; 29: 499-505.

4. Sharpe RM, Skakkebaek NE. Are oestrogens involved in falling sperm counts and disorders of the male reproductive tract? Lancet $1993 ; \mathbf{3 4 1}: 1392-5$.

5. Toppari J, Larsen JC, Christiansen P, Giwercman A, Grandjean P, Guillette LJ, Jr et al. Male reproductive health and environmental xenoestrogens. Environ Health Perspect 1996; 104 (Suppl 4):741-803.

6. Paulozzi LJ, Erickson JD, Jackson RJ. Hypospadias trends in two US surveillance systems. Pediatrics 1997; 100: 831-4.

7. Lund L, Engebjerg MC, Pedersen L, Ehrenstein V, Norgaard M, Sorensen HT. Prevalence of hypospadias in Danish boys: a longitudinal study, 1977-2005. Eur Urol. 2009; 55:1022-6.

8. Fisch H, Lambert SM, Hensle TW, Hyun G. Hypospadias rates in new york state are not increasing. J Urol 2009; 181: 2291-4.

9. Norgaard M, Wogelius P, Pedersen L, Rothman KJ, Sorensen HT. Maternal use of oral contraceptives during early pregnancy and risk of hypospadias in male offspring. Urology 2009; 74: 583-7.

10. Baskin LS, Himes K, Colborn T. Hypospadias and endocrine disruption: is there a connection? Environ Health Perspect 2001; 109: 1175-83. 
11. Yucesan S, Dindar H, Olcay I, Okur H, Kilicaslan S, Ergoren Y et al. Prevalence of congenital abnormalities in Turkish school children. Eur J Epidemiol 1993; 9: $373-80$.

12. Yesilipek MA, Melikoglu M, Anlar B, Balci S. Congenital anomalies in the Samsun region of Turkey. Turk J Pediatr 1989; 31: 253-63.

13. Yegane RA, Kheirollahi AR, Bashashati M, Rezaei N, Tarrahi MJ, Khoshdel JA. The prevalence of penoscrotal abnormalities and inguinal hernia in elementary-school boys in the west of Iran. Int J Urol 2005; 12: 479-83.

14. Manson JM, Carr MC. Molecular epidemiology of hypospadias: review of genetic and environmental risk factors. Birth Defects Res A Clin Mol Teratol 2003; 67: 825-36.

15. Leung TJ, Baird PA, McGillivray B. Hypospadias in British Columbia. Am J Med Genet 1985; 21: 39-50.

16. Silver RI, Rodriguez R, Chang TS, Gearhart JP. In vitro fertilization is associated with an increased risk of hypospadias. J Urol 1999; 161:1954-7.

17. Bauer SB, Retik AB, Colodny AH. Genetic aspects of hypospadias. Urol Clin North Am 1981; 8: 559-64.

18. Acemoglu H, Beyhun NE, Vancelik S, Polat H, Guraksin A. Thalassaemia screening in a non-prevalent region of a prevalent country (Turkey): is it necessary? Public health 2008; 122: 620-4.

19. Aschim EL, Haugen TB, Tretli S, Daltveit AK, Grotmol T. Risk factors for hypospadias in Norwegian boys - association with testicular dysgenesis syndrome? Int J Androl 2004; 27: 213-21.

20. Friedman T, Shalom A, Hoshen G, Brodovsky S, Tieder M, Westreich M. Detection and incidence of anomalies associated with hypospadias. Pediatr Nephrol 2008; 23:1809-16. 
21. Carmichael SL, Shaw GM, Nelson V, Selvin S, Torfs CP, Curry CJ. Hypospadias in California: trends and descriptive epidemiology. Epidemiology 2003; 14: 701-6.

22. Monteleone Neto R, Castilla EE, Paz JE. Hypospadias: an epidemiological study in Latin America. Am J Med Genet 1981; 10: 5-19.

23. Czeizel A, Toth J, Erodi E. Aetiological studies of hypospadias in Hungary. Hum Hered 1979; 29:166-71.

24. Fisch H, Golden RJ, Libersen GL, Hyun GS, Madsen P, New MI, et al. Maternal age as a risk factor for hypospadias. J Urol 2001; 165: 934-6.

25. Morales-Suarez-Varela MM, Toft GV, Jensen MS, Ramlau-Hansen C, Kaerlev L, Thulstrup AM et al. Parental occupational exposure to endocrine disrupting chemicals and male genital malformations: a study in the Danish National Birth Cohort study. Environ Health: a global access science source 2011; 10: 3.

26. Vrijheid M, Armstrong B, Dolk H, van Tongeren M, Botting B. Risk of hypospadias in relation to maternal occupational exposure to potential endocrine disrupting chemicals. Occup Environ Med 2003; 60: 543-50.

27. Nassar OH, Aklan HM. Erectile dysfunction among yemenis: does chewing khat pay a role? The Eurasian J Med 2014; 46: 69-73.

28. Pierik FH, Burdorf A, Deddens JA, Juttmann RE, Weber RF. Maternal and paternal risk factors for cryptorchidism and hypospadias: a case-control study in newborn boys. Environ Health Perspect 2004; 112:1570-6.

29. Henderson BE, Benton B, Cosgrove M, Baptista J, Aldrich J, Townsend D et al. Urogenital tract abnormalities in sons of women treated with diethylstilbestrol. Pediatrics 1976; 58: 505-7. 
30. Damber MG, von Schoultz B, Solheim F, Stigbrand T. A quantitative study of the pregnancy zone protein in sera of woman taking oral contraceptives. Am J Obstet Gynecol 1976; 124: 289-92.

31. Dean HJ, Winter JS. The effect of five synthetic progestational compounds on 5 alphareductase activity in genital skin fibroblast monolayers. Steroids1984; 43:13-24.

32. Raman-Wilms L, Tseng AL, Wighardt S, Einarson TR, Koren G. Fetal genital effects of first-trimester sex hormone exposure: a meta-analysis. Obstet Gynecol 1995; 85: $141-9$.

33. Ericson A, Kallen B. Congenital malformations in infants born after IVF: a populationbased study. Hum Reprod. 2001; 16: 504-9.

34. Carmichael SL, Shaw GM, Laurent C, Croughan MS, Olney RS, Lammer EJ. Maternal progestin intake and risk of hypospadias. Arch Pediatr Adolesc Med. 2005; 159: 957- 62.

35. Campbell MF. Anomalies of the genital tract. In: M.F. Campbell, Harrison JH, editors. Urology. 2. Philadelphia: WB Saunders; 1970. 1573-607.

36. Hsieh JT, Wong WY, Chen J, Chang HJ, Liu SP. Congenital isolated penile torsion in adults: untwist with plication. Urology 2002; 59: 438-40.

37. Cheng PK, Chanoine JP. Should the definition of micropenis vary according to ethnicity? Horm Res 2001; 55: 278-81.

38. Cinaz P, Yesilkaya E, Onganlar YH, Boyraz M, Bideci A, Camurdan O et al. Penile anthropometry of normal prepubertal boys in Turkey. Acta Paediatr 2012; 101: e33-6.

39. Skakkebaek NE, Rajpert-De Meyts E, Main KM. Testicular dysgenesis syndrome: an increasingly common developmental disorder with environmental aspects. Hum Reprod 2001;16: 972-8. 
40. Services fadadohah. 64 fr 17985 - progestational drug products for human use;

requirements for labeling directed to the patient.Federal Register Volume 64 (Issue 70 (April 13, 1999)): 17985-8. 